\title{
Comparison of mosquito nets, proguanil hydrochloride, and placebo to prevent malaria
}

\author{
C G Nevill, W M Watkins, J Y Carter, C G Munafu
}

\begin{abstract}
One hundred and ninety students aged 6 to 18 at a boarding school $120 \mathrm{~km}$ west of Nairobi in the Rift Valley participated in a comparative trial of malaria prophylaxis. Treatment with a combination of amodiaquine $25 \mathrm{mg} / \mathrm{kg}$ over three days plus doxycycline $100 \mathrm{mg}$ twice daily for five days cleared their blood of Plasmodium falciparum. They were then randomly divided into the following three groups matched for age and sex: one group slept under mosquito nets; one group received one or two tablets (100 $\mathrm{mg}$ each) of proguanil hydrochloride daily according to weight; one group received one or two placebo tablets daily which were the same size and colour as the proguanil tablets. Malaria was diagnosed when asexual $\boldsymbol{P}$ falciparum were seen on blood films and was treated with pyrimethaminesulphadoxine. At the end of one school term 188 of the 190 students had completed the study.

One new infection was found during $\mathbf{3 8 9 3}$ days of follow up in the mosquito net group, eight new infections over 3667 days in the proguanil group, and 35 new infections over 3677 days in the placebo group, representing a reduction of $97 \cdot 3 \%$ and $77 \cdot 1 \%$ in attack rates for the mosquito net method and for treatment with proguanil respectively. Both provide effective protection from malaria.
\end{abstract}

\section{Introduction}

National programmes for the control or eradication of malaria have traditionally been based on vector control, clinical case finding, treatment, and chemoprophylaxis. ' Countries with restricted budgets for health care, however, cannot support such programmes, ${ }^{2}$ and thus coordination within the existing community health care structure for the control of malaria is being encouraged. This decreases the economic burden, but simple, effective "tools" need to he available.

Mosquito nets were uscd extensively and with good results as a method of vector control before the advent and widespread availability of chemoprophylaxis, ${ }^{+}$and they may have a role again. Also, the increasing resistance to chloroquine," the similarity in malaria attack rates in American travellers who have had and not had chloroquine treatment, and concern over the toxicity of alternative prophylactic antimalarial drugs $^{8.10}$ have led to a revived interest in the biguanides (proguanil and chlorproguanil) for preventive treatment. Biguanides are dihydrofolate reductase inhibitors which have causal as well as suppressive activity and minimal toxicity after prolonged use.

No controlled studies of the efficacy of proguanil have been carried out in eastern Africa over the past two decades, although retrospective data from residents in Dar-es-Salaam imply that a dose of $200 \mathrm{mg}$ a day is protective. " In a recent study of the efficacy of chlorproguanil at Jilore, Kenya, however, the recom- mended weekly dose of $20 \mathrm{mg}$ was found to give inadequate protection. Therefore, in this study we compared the use of mosquito nets with treatment with proguanil and placebo as protection from malaria.

\section{Methods}

The boarding school was situated $120 \mathrm{~km}$ west of Nairobi, Kenya, on the western wall of the Great Rift Valley, at an altitude of $630 \mathrm{~m}$ and with a mean daily temperature of $28^{\circ} \mathrm{C}$. According to Ministry of Health statistics this is an area of pronounced seasonal malarial transmission, but irrigation schemes have recently stabilised transmission. ${ }^{\text {i i }}$ There is resistance to chloroquine and amodiaquine (unpublished observations), but a high degree of susceptibility to pyrimethaminesulphadoxine. There is a dispensary $800 \mathrm{~m}$ from the school run by a dispensary nurse, and during the trial a laboratory technologist was stationed there.

The school takes both boys and girls, age range 6-16 years, and they are drawn largely from the nomadic Maasai of the southern Rift Valley, an area of 8000 $\mathrm{km}$ '. Before recruiting pupils we held barazas (meetings) with the parents, chiefs, and the school committee to ensure that all concerned consented to and understood the nature of the trial.

\section{INVESTIGATIONS}

Pupils were sequentially allocated by class to the three study groups. The first group slept under nylon single mosquito nets on the upper bed of double bunks in dormitories housing eight pupils. The second group received proguanil hydrochloride tablets daily $(100 \mathrm{mg}$ size), and the third group received placebo tablets daily matched for size and colour to the proguanil tablets. Both proguanil and placebo tablets were given according to weight: pupils weighing $\leqslant 30 \mathrm{~kg}$ received one tablet, those weighing $31-60 \mathrm{~kg}$ two tablets. The pupils were blind to their allocation. The nets were made locally from material with roughly six holes per $\mathrm{cm}$, and they were protected from the coarse concrete walls of the dormitories by a large cotton skirt.

At recruitment a full history was taken and a full examination carried out, including taking the temperature by mouth, weighing, and checking the size of the spleen. Investigations included measuring haemoglobin and urinary 4 aminoquinoline ${ }^{1 x}$ concentrations and looking for malaria parasitaemia (thick blood films (Field stain) examined completely under oil immersion, with parasites counted/300 leucocytes and species confirmed on thin film (reverse Field stain $\left.{ }^{19}\right)$ ). All pupils were then treated with amodiaquine $25 \mathrm{mg} / \mathrm{kg}$ over three days plus doxycycline $100 \mathrm{mg}$ twice daily for five days by one of us. The urine test was repeated on day one to confirm amodiaquine absorption, and the effectiveness of the regimen was assessed by making thick blood films daily until parasites cleared and then again on days seven and 14 . On day five, the day after completing
Correspondence to: Dr Nevill. 
treatment, the pupils began sleeping under mosquito nets and taking proguanil and placebo. The tablets were taken at breakfast and recorded by a teacher, and this was also recorded weekly on a randomly chosen day by one of us who was always blind to the subject. The mosquito nets were untied and tucked in at 1700; this was checked periodically by the night duty master and one of us. The pupils were usually in bed by 2200 , and in the morning the nets were folded and tied up. Once a week the matron would examine the nets for holes and tears, which were repaired with the sewing kits provided. No insecticides were used.

The children were monitored for malaria in two ways. Firstly, any child who reported sick was sent to the dispensary where he or she was examined by a nurse and thick and thin blood films taken. Secondly, all the pupils in the trial were followed up every two weeks when a thick blood film was taken and examined. On all occasions the slides were labelled with the study number, whose group was unknown and hence blind to the reader. Malaria was diagnosed from a positive blood film, and a negative result was recorded only after the whole film had been examined. All malarial episodes were treated with a single dose of pyrimethaminesulphadoxine (one tablet $=25 \mathrm{mg}$ pyrimethamine +500 mg sulphadoxine) according to the regimen: weight

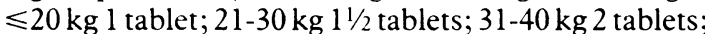
$41-50 \mathrm{~kg} \mathrm{2} 1 / 2$ tablets; $51-60 \mathrm{~kg} 3$ tablets. Parasitaemia and clinical recovery were monitored daily until parasitaemia cleared and then on days seven, 14, 21, and 28. Children were withdrawn from trial analysis for 28 days.

For other illnesses (blood film negative) the nurse managed the patient according to the clinical findings and did not give any drug with known antimalarial activity, such as trimethoprim-sulphamethoxazole and tetracycline. A radio link between the school and the African Medical Research Foundation (Flying Doctor Service), Nairobi, enabled the nurse to obtain advice from one of us when necessary. Some children were absent during the trial and on returning were reintroduced to their group and followed up for 14 days. If they became parasitaemic they were treated as above and included again in the trial after 28 days. If aparasitaemic after the 14 days they were included in the analysis again from day 15 .

At the end of the school term the children's weight was taken again and haemoglobin measured again for comparison with the values at recruitment. Preliminary analysis was immediately performed to assess significance in view of the planned subject cross over for the second term.

\section{Results and analysis}

Altogether 190 children were recruited; two were lost to follow up, one to the hospital at Magadi for treatment of tuberculosis, the other to his family to herd cattle.

TABLE I-Details of 188 pupils in trial

\begin{tabular}{|c|c|c|c|c|}
\hline & & \multicolumn{3}{|c|}{ Trial groups: } \\
\hline & & Placebo & Proguanil & Mosquito nets \\
\hline Total No & & 68 & 59 & 61 \\
\hline Boys & & 48 & to & 38 \\
\hline Girls & & 20 & 19 & 23 \\
\hline Mean age (range) (years) & & $11 \cdot 9(6-17)$ & $11 \cdot 8(6-18)$ & $12 \cdot 3(7-18)$ \\
\hline Mean initial weight ( rang & ge) $(\mathrm{kg})$ & $31 \cdot 1(15-52)$ & $29 \cdot 4(16-45)$ & $32 \cdot 2(1+-58)$ \\
\hline \multicolumn{5}{|c|}{$\begin{array}{l}\text { Mean initial haemoglobin (range) } \\
(\mathrm{g} / \mathrm{dl})\end{array}$} \\
\hline Mean temperature $\left({ }^{\circ} \mathrm{C}\right)$ & & $37 \cdot 45(36 \cdot 5-38 \cdot 2)$ & $37 \cdot 5 \cdot 37 \cdot 38 \cdot 5$ & $37+36 \cdot 6-38$ \\
\hline No spleen positive & day 0 & 19 & 19 & 20 \\
\hline No parasitaemic & & 31 & 31 & 18 \\
\hline \multicolumn{5}{|c|}{$\begin{array}{l}\text { Geometric mean asexual parasites } \\
\left(\mathrm{mm}^{3}\right)\end{array}$} \\
\hline Day 0 & & $200 \cdot 5$ & $164 \cdot 7$ & $387 \cdot 3$ \\
\hline Day 1 & & $15 \cdot 6$ & $6 \cdot 8$ & $33 \cdot 4$ \\
\hline Day 2 & & $1 \cdot 14$ & $1 \cdot 46$ & $2 \cdot 36$ \\
\hline Day 3 & & & & 1.64 \\
\hline
\end{tabular}

The remainder were followed up for a school term of 84 days. Assessment of protection was started on day 14, once they were clear of the effects of the clearance drugs. The preliminary analysis showed such significant protection with proguanil and mosquito nets that it was unethical to carry out the cross over for a second term.

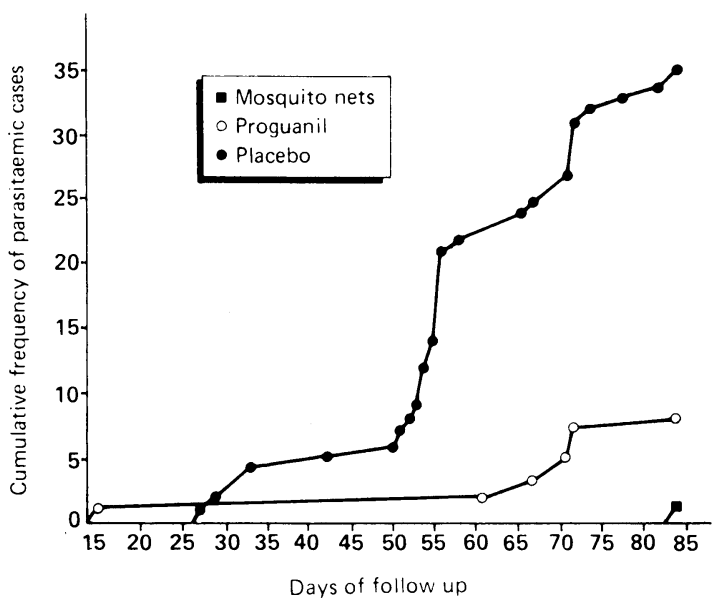

Cumulative frequency of cases of parasitaemia in the three trial groups by length of follow up

Table 1 gives details of the 188 pupils. There was no significant difference between the groups in age, sex, weight, haemoglobin concentrations, or spleen rate (Kruskal-Wallis analysis of variance by rank, with approximation to $\chi^{2}$ for large samples). The geometric mean parasitaemia $/ \mathrm{mm}^{2}$ for all parasitaemic pupils was 215 on day $0,13.4$ on day $1,1.48$ on day 2 , and $1 \cdot 12$ on day 3 . All were cleared of $P$ falciparum on the regimen of amodiaquine and doxycycline, with a mean clearance time of 1.55 days and no reappearance of parasitaemia during 28 days of follow up (table I). The urine test converted from negative to positive in all pupils on day 1 , confirming 4 aminoquinoline absorption. There was no significant change in the mean group weight or haemoglobin concentrations at the end of the trial (two tailed test).

\section{TOXICITY}

There was no observed reported toxicity in the group taking placebo and the pupils tolerated the mosquito nets well. Eight children in the proguanil group, however, complained of nausea initially but remained on prophylactic treatment and were free of nausea after one week. Another child had widespread urticaria over the chest and stomach and felt hot without fever. This responded to treatment with antihistamines and drug withdrawal, and he was exchanged with a pupil matched for age and sex in the placebo group during the period covered by the clearance regimen and before the start of the analysis.

\section{NEW INFECTIONS}

By the time the study was completed there had been 35 infections in the placebo group, eight in the proguanil group, and one in the group using mosquito nets (table II). The cumulative frequency distribution of the new episodes of infection by group is shown in the figure; the two episodes before day 28 occurred in pupils who were not initially parasitaemic. The presenting geometric mean parasitaemia for the proguanil group $\left(289 / \mathrm{mm}^{3}\right)$ was significantly lower than for the placebo group $\left(2040 / \mathrm{mm}^{i}\right)(\mathrm{p}<0 \cdot 01)$, although all new infections cleared successfully with pyrimethaminesulphadoxine treatment, with a mean clearance time of 1.83 days. One pupil in the placebo group after treatment on day 50 was again parasitaemic on day 78 . This was considered to be reinfection rather than recrudescence. There were no other episodes of para- 


\begin{tabular}{lccc}
\hline & & Trial groups: & \\
\cline { 2 - 4 } & Placebo & Proguanil & Mosquito nets \\
\hline No(\% of whole group) & $35(51)$ & $8(14)$ & $1(2)$ \\
Total No of follow up days & 3677 & 3667 & 3893 \\
Average No of days in the study & 54.07 & 62.15 & 63.82 \\
Attack rate per 100 person weeks & 6.67 & 1.53 & 0.18 \\
\hline
\end{tabular}

sitaemia within 28 days of treatment, and there were no mixed infections.

Although between groups there was a significant difference in the numbers of pupils with parasitaemia at the outset $\left(\chi^{2}=6.911\right.$, df $\left.2, p<0.05\right)$, there was no correlation between parasitaemia at the outset and the development of parasitaemia during follow up (placebo group: $\chi^{2}=2 \cdot 19$, df $1,0 \cdot 1<p<0 \cdot 2$; proguanil $p=0 \cdot 29$, Fisher's exact test, a more rigorous test for small numbers). Compared with the placebogroup, however, there was a highly significant reduction in the number of new episodes of malaria for the mosquito net and proguanil groups (table II) (placebo $v$ mosquito net: $\chi^{2}=47 \cdot 38, \mathrm{df}=1, \mathrm{p}<0.001$; placebo $v$ proguanil: $\chi^{2}=$ $25 \cdot 6, \mathrm{df}=1, \mathrm{p}<0.001$ ) but a less significant difference between the proguanil and mosquito net groups $\left(\chi^{2}=\right.$ $6.34, \mathrm{df}=1,0.01<\mathrm{p}<0.05)$. Since the risk of infection is proportional to the length of exposure expected values were weighted by the factor: average number of person days per group divided by the average number of person days for all pupils. Therefore for proguanil the factor was $(3667 \div 59) /(11237-188)=62 \cdot 15 / 59 \cdot 77$ $=1 \cdot 04$.

\section{Discussion}

The use of plain mosquito nets resulted in appreciable protection from malaria $(97 \cdot 3 \%)$. Unfortunately, because some people have a mosquito net those who are not protected by nets may receive more mosquito bites. ${ }^{20}$ Thus in our study the risk of infection for the proguanil and placebo groups may have been artificially increased. None the less, while the results of a single study should be viewed with caution, our results concur with the findings in the Farafenni area of The Gambia where there was an appreciable inverse correlation between splenomegaly and the use of bed nets. 'Using an insecticide on nets and curtains seems to strengthen this vector barrier even when there are holes and tears, ${ }^{212}$ which may increase the economic feasibility of using bed nets because they can be used for a long time and a larger mesh can be used (present cost of a single net about 160 Kenya shillings $(\mathrm{K} /-)=$ about $£ 6$, spread over five years, $32 \mathrm{~K} /$ - or $£ 1.14$ a year).

The saving in days lost from studying and attending classes because of illness is also important. In this school the rates for the placebo group suggest that of 190 boarders over 12 weeks (one term), about 152 would be expected to suffer an episode of malaria, which represents a considerable period of compromised learning capacity, Indeed, since the end of the trial, when all the children were given nets, the headmaster has reported a pronounced decrease in referrals to the dispensary. (In a blind 18 month follow up the nets were found to be in impeccable condition.) The $77 \cdot 1 \%$ protection rate with proguanil alone is further evidence of its efficacy in eastern Africa. Furthermore, in recent studies in vivo the findings suggest that taking chlorproguanil daily may be more effective than taking proguanil daily (Watkins, unpublished observation), which support the earlier in vitro findings. ${ }^{23}$ Significantly lower parasitaemia was found in the pupils in the proguanil group who developed malaria compared to those in the placebo group, and this may decrease the risk of developing serious malaria before clinical

presentation. Proguanil, however, is not considered a practical alternative for general use in the endemic population owing to cost $(190 \mathrm{~K} /-(£ 6.80)$ per person year $v$ chloroquine $25 \mathrm{~K} /-(£ 0.90)$ and mosquito nets) compliance, and the probable role of chemoprophylaxis in the more rapid selection of resistance in endemic areas. ${ }^{2+}$ Whether travellers should use proguanil in addition to mosquito nets is debatable.

The one subject who showed acute type 1 hypersensitivity suggests a serious side effect to proguanil that we believe has not been previously reported. Amodiaquine plus doxycycline seems to be an effective alternative regimen for the treatment of $P$ falciparum malaria in this area. The mean clearance time of 1.55 days compares favourably with that of pyrimethaminesulphadoxine ( 1.83 days), but it is less cost effective at $16340 \mathrm{~K} /-(£ 583) v 8600 \mathrm{~K} /-(£ 307)$ per 1000 patient treatments.

This study was part of a collaborative programme between the BSRC, KEMRI, and AMREF. The costs were covered by the Wellcome Trust and AMREF, and we thank ICI for the supply of proguanil and placebo. The work would not have been possible without the help and cooperation of the pupils and masters of the school, especially $\mathrm{Mr}$ James Selel, headmaster, and $\mathrm{Mr}$ Murithi.

We thank the dispensary staff, $\mathrm{Mr}$ Albert Munyere and $\mathrm{Mr}$ Joseph Simile; Mr D Anyona, Mr C Kanja, and Mr D Muchava for laboratory work; and Mrs E Griffiths for statistical analysis. We also thank Professor Mugambi, Director of KEMRI, for permission to publish

1 Bruce-Chwatt LJ. Essential malariologv. 2nd ed. London: Heinemann, $1986: 360-2$

2 Yung-han P. Malaria situation in the western Pacific region. In: Siddiqui WA, ed. Asia and Pacific conference on malaria. Honolulu, Hawaii, 1985:

3 Beales PF, Nájera JA, Tarimo E, et al. Malaria control as part of primary health care; report of WHO study group. Tech Rep Ser 1984;No 712:7.

4 Winter PE, Cadigan FC, Thienanum W, Cavanaugh DC. Malaria discipline as prophylaxis. Military Medicine 1967;132:917-9.

5 Bradley AK, Greenwood BM, Greenwood AM, et al. Bed nets and morbidity from malaria. Lancet 1986;ii:204-7.

6 World Health Organisation. Weekly Epidemiological Record. 1987;62 (22) $158-61$.

7 Lobel HO, Campbell CC, Roberts JM. Fatal malaria in US' civilians. Lance $1985 ; \mathrm{i}: 873$.

8 Miller DK, Lobel HO, Satriale RF, Kuritsky JN, Stern R, Campbell CC. Severe cutaneous reactions among American travellers using pyrimethaminesulfadoxine (Fansidar) for malaria chemoprophylaxis. Am J Trop Med $H y$ 1986;35:451-8

9 Neftel KA, Woodtly W, Schmid M, Frick PG, Fehr J. Amodiaquine induced agranulocytosis and liver damage. Br Med f 1986;292:721-3.

10 Bruce-Chwatt LJ, Hutchinson DBA. Maloprim and agranulocytosis. Lancet 1983;ii:1487-8.

11 Curd FHS, Davey DG, Rose FL. Studies in antimalarial drugs, X. Some biguanide derivatives as new types of antimalarial substances with both therapeutic and causal prophylatic activity. Ann Trop Med Parasito $1945 ; 39: 208-16$

12 Bruce-Chwatt LJ, ed. Chemotherapy of malaria. Rev 2nd ed. WHO Monog Ser 1986; No 27:72

13 McLarty DG. Chemoprophylaxis of malaria in non-immune residents in Dares-Salaam, Tanzania. Lancet 1984; ii:656-9.

14 Watkins WM, Brandling-Bennett AD, Oloo AJ, Howells RE, Gilles HM, Koech DK. Inadequacy of chlorproguanil $20 \mathrm{mg}$ per week as chemoprophylaxis for falciparum malaria in Kenya. Lancet 1987;i:125-6.

15 King B, ed. Annual report nomadic health unit. Nairobi: African Medical Research Foundation, 1984

16 King B, ed. Annual report nomadic health unit. Nairobi: African Medical Research Foundation, 1985

17 Watkins WM, Brandling-Bennett AD, Nevill CG, Carter JY, Boriga DA Howells RA. Chlorproguanil/daposone for the treatment of non-severe falciparum malaria in Kenya. A pilot study. Trans $R$ Soc Trop Med Hyg (in press).

18 Lelijveld J, Kortmann H. The eosin colour test of Dill-Glazko; a simple field test to detect chloroquine in urine. Bull WHO 1970;42:477-9.

19 Carter JY, Lema O. Field stain revisited. In: Sezi C, ed. Proceedings of the annual conference of the physicians of East and Central Africa, 1986. Kampala: Ministry of Health, 1987.

20 Port GR, Boreham PFL. The effect of bed nets on feeding by Anopheles gambiae Giles (Diptera: Culicidae). Bulletin of Entomological Reseurch 1982;72:483-8.

21 Majori G, Sabatinilli G, Coluzzi M. Efficacy of permethrin-impregnated curtains for malaria vector control. Medical and Veterinary Entomologv 1987;1:185-92.

22 Darriet F, Robert V, Tho Vien N, Carnevale P. Evaluation of the efficacy of permethrin-impregnated intact and perforated mosquito nets against vectors of malaria. Geneva: World Health Organisation, 1984. (VBC/84.899 vectors of malaria. Geneva:
(mimeographed document))

23 Sixsmith DG, Watkins WM, Chulay JD, Spencer HC. In vitro antimalarial activity of tetrahydrofolate dehydrogenase inhibitors. Am $\mathcal{f}$ Trop Med $H y$ activity of tetrahy

24 Canfield CJ, Goodwin L, Kaseje DCO, et al. Advances in malaria chemotherapy. WHO expert scientific report. WHO Tech Rep Ser 1984;No 711:28.

(Accepted 5 Mav 1988) 